\title{
Measuring Changes in the Economics of Medical Practice
}

\author{
Christopher Fleming, MPH, Eugene Rich, MD, Catherine DesRoches, DrPH, James Reschovsky, PhD, \\ and Rachel Kogan, MPH
}

Mathematica Policy Research, Princeton, NJ, USA.

For the latter third of the twentieth century, researchers have estimated production and cost functions for physician practices. Today, those attempting to measure the inputs and outputs of physician practice must account for many recent changes in models of care delivery. In this paper, we review practice inputs and outputs as typically described in research on the economics of medical practice, and consider the implications of the changing organization of medical practice and nature of physician work. This evolving environment has created conceptual challenges in what are the appropriate measures of output from physician work, as well as what inputs should be measured. Likewise, the increasing complexity of physician practice organizations has introduced challenges to finding the appropriate data sources for measuring these constructs. Both these conceptual and data challenges pose measurement issues that must be overcome to study the economics of modern medical practice. Despite these challenges, there are several promising initiatives involving data sharing at the organizational level that could provide a starting point for developing the needed new data sources and metrics for physician inputs and outputs. However, additional efforts will be required to establish data collection approaches and measurements applicable to smaller and single specialty practices. Overcoming these measurement and data challenges will be key to supporting policy-relevant research on the changing economics of medical practice.

KEY WORDS: physician practice; input; output; scale economy; efficiency. J Gen Intern Med 30(Suppl 3):S562-7

DOI: $10.1007 / \mathrm{s} 11606-015-3368-5$

(C) Society of General Internal Medicine 2015

\section{INTRODUCTION}

In the basic microeconomic theory of the firm, units of capital and labor are combined to produce a market good or service. The optimal production function combines inputs in quantities such that the firm produces the greatest output for a given aggregate input cost —or, conversely, minimizes costs given a fixed quantity of output. Since the 1970s, economists and healthcare researchers have estimated output production and input cost functions for physician practices. These studies investigate the costs of producing physician services, ${ }^{1}$ the input combinations most efficiently combined to produce physician services, ${ }^{2}$ and the economies of scale in the provision of physician services. ${ }^{3}$

Published online June 24, 2015
In a recent review of literature on scale and scope economies in physician practice organizations, Burns and colleagues noted there has been rapid growth in very large physician practices, but that most physicians continue to practice in smaller and single-specialty practices. ${ }^{4}$ Further, Burns et al. found the "evidence of scale economies, scope economies, and quality performance advantages [for larger groups] has been strikingly thin, in some cases for decades." Given ongoing physician payment reforms, and concerns these can motivate opportunistic integration of physicians into larger organizational entities of uncertain value to patients, ${ }^{5-7}$ the impact of practice consolidation on the economics of physician practice remains an important policy research question.

In this paper, we explore current issues relevant to defining and measuring the inputs and outputs of physician practice. Utilizing the recent review by Burns et al., ${ }^{4}$ as well as supplemental searches of EBSCOhost, PubMed and MEDLINE, and Google Scholar for articles published since 1980, we review practice inputs and outputs as typically described in the literature on the economics of medical practice, as well as new considerations relevant to the evolving nature of physician work. We identify the conceptual challenges for defining these "inputs" and "outputs" in a complex and evolving health care system. We note the pragmatic difficulties with finding the data needed, as well as the methodological challenges that must be overcome to obtain reliable measures of inputs and outputs across practice organization types and physician roles. We also note some promising recent developments that hold potential for further advances in the data sources and measurement approaches needed to support policy-relevant research on the changing economics of medical practice.

\section{PRODUCTION FUNCTIONS FOR PHYSICIAN PRACTICE}

Researchers attempting to model physician production functions have typically estimated the effects of various inputs (e.g., physician and non-physician labor, office space, medical equipment) on physician outputs (e.g., office visits or procedures). While researchers have used various methods to estimate production functions for physician services, the basic form of the equations employed has been relatively consistent since the 1970s. In a 1972 paper, Reinhardt provided an exemplar physician production function: $Q=f\left(H, X_{1}, X_{2}, \ldots\right.$, $\left.X_{n}\right){ }^{8}$ In this equation, $Q$ denotes rate of output produced by the physician's practice and $H$ is the rate of input of the 
physician's time (e.g., hours per week in practice). The elements of "vector X" represent quantities of inputs such as capital equipment and non-physician labor.

\section{THE CONCEPTUAL CHALLENGE: WHAT ARE THE INPUTS AND OUTPUTS OF PHYSICIAN PRACTICE? What are Practice Inputs?}

Our scan of the literature on the economics of physician practice identified a number of categories of practice inputs (Table 1). However, there have been numerous technological changes that have affected the inputs into physician practice, including point-of-care laboratory testing and imaging, robotassisted surgery, and, of course, health information technology (HIT) (Table 2). Changes in professional responsibilities, either derived from within the profession or externally mandated by payers, purchasers or societal expectations, have also changed practice inputs. Examples include professional effort devoted to developing care plans, care coordination, shared decision-making, quality improvement, and quality reporting. Although newer inputs such as HIT, imaging technology, and care management staff might be categorized under traditional input categories (for example, facilities and practice administration), they reflect new and evolving contributions to physician production. Furthermore, as described in more detail elsewhere in this issue ${ }^{18}$ these expanded types of inputs may be supported by different entities in the changing landscape of practice organizational affiliations.

\section{What are the Outputs from Physician Work?}

If the conceptual challenges of defining practice inputs have become more complex in recent years, those for measuring the output from physician work have become quite daunting (see Table 2). As described elsewhere in this special issue, there are many iterative steps involved in good medical care ${ }^{18}$ Some of these (for example, initial evaluation, diagnostic testing, and therapeutic interventions) have historically been characterized

Table 1 Traditional Categories of Practice Inputs

\begin{tabular}{|c|c|}
\hline Input Categories & Examples \\
\hline Physician Labor ${ }^{1,2,9-16}$ & $\begin{array}{l}\text { Number full-time employees; hours per } \\
\text { week in practice }\end{array}$ \\
\hline $\begin{array}{l}\text { Clinical support staff } \\
\text { labor }^{1-3,9,11,13-17}\end{array}$ & $\begin{array}{l}\text { Number of full-time employees (e.g., } \\
\text { non-physician providers such as regis- } \\
\text { tered nurses or medical assistants) }\end{array}$ \\
\hline $\begin{array}{l}\text { Facilities or office } \\
\text { space }^{2,9,11,13,15,16}\end{array}$ & $\begin{array}{l}\text { Office rental; medical records; } \\
\text { computing }\end{array}$ \\
\hline $\begin{array}{l}\text { Medical } \\
\text { equipment }^{2,9,11,13,16}\end{array}$ & Radiological equipment \\
\hline Supplies ${ }^{11,13,16}$ & $\begin{array}{l}\text { In-office ancillary services (e.g., } \\
\text { laboratory) }\end{array}$ \\
\hline Malpractice insurance ${ }^{13}$ & NA \\
\hline Practice administration $^{13,16}$ & $\begin{array}{l}\text { Billing; insurance company contracting } \\
\text { and monitoring; accounting and payroll; } \\
\text { marketing and promotion; legal and } \\
\text { consulting; housekeeping, maintenance, } \\
\text { and security }\end{array}$ \\
\hline
\end{tabular}

Table 2 Current Challenges to Research on Economics of Physician Practice

\begin{tabular}{|c|c|c|}
\hline Challenge & Inputs & Outputs \\
\hline $\begin{array}{l}\text { Conceptual } \\
\text { Issues }\end{array}$ & $\begin{array}{l}\text { Technological changes } \\
\text { in practice (e.g., HIT, } \\
\text { point of care imaging) } \\
\text { Changing professional } \\
\text { responsibilities (e.g., } \\
\text { care planning, care } \\
\text { coordination) }\end{array}$ & $\begin{array}{l}\text { Broader range of } \\
\text { services offered in } \\
\text { physician practices. } \\
\text { Varying quality and } \\
\text { appropriateness of indi- } \\
\text { vidual services } \\
\text { provided } \\
\text { Limited applicability of } \\
\text { aggregate measures of } \\
\text { output (e.g., episodes } \\
\text { of care, populations } \\
\text { managed) to diverse } \\
\text { physician roles }\end{array}$ \\
\hline Data Sources & $\begin{array}{l}\text { Physician practice site } \\
\text { Physician organization } \\
\text { owning the practice } \\
\text { Hospital location affili- } \\
\text { ated with the practice } \\
\text { Other resource- } \\
\text { contributing affiliates } \\
\text { (e.g., PHO, IPA) }\end{array}$ & $\begin{array}{l}\text { Many physicians } \\
\text { provide services in } \\
\text { multiple locations } \\
\text { Many physicians bill } \\
\text { from multiple different } \\
\text { practice organizations }\end{array}$ \\
\hline $\begin{array}{l}\text { Measurement } \\
\text { Considerations }\end{array}$ & $\begin{array}{l}\text { Diverse physician } \\
\text { awareness of inputs into } \\
\text { their practice } \\
\text { Diverse roles and re- } \\
\text { sponsibilities of } \\
\text { "administrators" for } \\
\text { practice sites } \\
\text { Diverse models for al- } \\
\text { locating input costs } \\
\text { across organizations and } \\
\text { practice locations }\end{array}$ & $\begin{array}{l}\text { Relative value units } \\
\text { (RVUs) poorly cali- } \\
\text { brated method for enu- } \\
\text { merating billable } \\
\text { physician output } \\
\text { Important physician } \\
\text { outputs not measured } \\
\text { thru RVUs (e.g., } \\
\text { emails, telephone } \\
\text { advice) } \\
\text { No ready measures of } \\
\text { work output of clinical } \\
\text { teams }\end{array}$ \\
\hline
\end{tabular}

as the types of professional "outputs" purchased by patients. With the rise of third-party payers, these became the basis of fee-for-service physician payments in many systems of reimbursement around the globe. Other professional actions (prioritizing patient concerns, formulating a differential diagnosis, care coordination, and promoting patient adherence to testing or treatment recommendations) are not as readily quantifiable as distinct services, and thus, have been specifically purchased less often through fee-for-service mechanisms.

In the reviewed literature on the economics of physician practice, production of discrete physician services (for example, physician visits and procedures) have been the outputs typically analyzed by researchers. Output metrics included visits per week, ${ }^{1,17}$ as well as more detailed enumerations of nonsurgical, surgery and anesthesiology, clinical lab, pathology, and diagnostic radiology and imaging procedures. ${ }^{2,13,14}$ Some studies have also looked at some measure of practice revenue as an output. ${ }^{3,11,13,16}$ However, because medical prices typically have little relationship to actual costs or quantity of output, our focus will be on medical services, not revenue.

Of course, technological advances, as well as physician entrepreneurship, have expanded the range of services patients may obtain from medical practices. ${ }^{19,20}$ Given the increasing range of services provided by physicians, some more recent studies have moved away from counts of discrete services to 
aggregate measures of outputs like relative value units (RVUs). ${ }^{13,21,22,38}$ Derived from the Resource-Based Relative Value Scale (RBRVS), RVUs provide a measure of output that account for both the mix (based on relative resource intensity) and the number of services provided by physicians.

RVUs also fall short, however, as a conceptual metric for the output from a physician or their practice. For example, RVUs do not address the appropriateness of the service provided. $^{23,24}$ Therefore, a physician providing many highintensity procedures might appear very productive on the basis of RVUs generated, but might be providing substantial amounts of unnecessary care. Highly specific appropriateness criteria and quality measures would be needed to measure different physicians' relative performance of clinical roles. Within cardiology, for example, performance measures for interventional cardiologists treating patients with coronary artery disease would provide no information on the appropriateness or quality of services provided by cardiologists focused on electrophysiological services to patients with arrhythmia.

Given these problems with individual services as a measure of physician output, other conceptual approaches have emerged in recent years for quantifying this construct. For example, measuring care for specific episodes of illness provides a focus on patient's health problems as well as considering the efficiency and quality of care. Unlike measures based on work RVUs, episode-based metrics can detect inefficiencies such as duplicative tests or hospital admissions. However, there are a variety of challenges to an episode-based approach to measuring practice outputs even in a single specialty like cardiology. While some cardiologists manage episodes of acute cardiac illness (for example, acute myocardial infarction, unstable angina, or atrial fibrillation), others play a more limited, technical role in care (for example, the interventional cardiologist focused on work in the catheterization lab). Such physicians may play a role in many episodes of cardiac illness, but have little or no responsibility for the overall efficiency or care quality of any single episode.

Furthermore, using episodes as the unit of physician output does not resolve whether care delivered during the episode was appropriate. Variation in problem identification, testing, diagnosis, and treatment may contribute to which episodes are identified within a population. Thus, one cannot assume episode-defining diagnoses are correct or procedures appropriate. $^{25}$ Moreover, episode-based approaches to measuring output do not value work done to avert future episodes (for example, prevention and chronic disease management).

These limitations to episode-based approaches to measuring physician output are highlighted when considering their application to primary care. The work of care coordination, patient centeredness, and comprehensiveness are not readily measured through enumerating episodes of illness, so primary care lends itself to a focus on a patient population. However, in the current U.S. health care system, understanding the actual level of patient responsibility held by individual primary care physicians is challenging. The role of the primary care physician in care received by patients varies substantially from setting to setting, ${ }^{26,27}$ and patient attribution and severity adjustment pose daunting challenges to population based metrics of physician output. ${ }^{28-30}$

Thus, there may be no one metric for the output of physician work that can be applied to all physicians in all settings. For example, while work RVUs might be an effective way to capture the daily work of a radiologist or an interventional cardiologist, the lack of RVUs for care coordination or advanced access (such as telephone or email communication) render them of limited value in measuring outputs for a family physician or a cardiologist managing heart failure patients. Although some of the work of family medicine might be observed through measuring quality-adjusted episodes of care, the role of a cardiologist can vary from episode manager to proceduralist, and radiologists typically direct the care of few episodes, while contributing to many. Regarding populationbased measures such as overall cost and outcome, the work of individual radiologists or interventional cardiologists will typically be only one factor in determining the health of patients for whom they provide services.

\section{THE PRACTICAL CHALLENGE: WHERE ARE THE INPUT AND OUTPUT DATA? Potential Sources of Input Data}

As noted earlier, the changing landscape of practice organizational affiliations creates new challenges to the researcher attempting to collect data relevant to measuring the economics of physician practice. To illustrate the challenge of enumerating relevant practice inputs in the US today, consider the example of interventional cardiology. An interventional cardiologist might practice in a cardiology group that manages its own outpatient clinics, cardiac catheterization suites, staff, equipment, and specialty-specific information technology infrastructure. Alternatively, the staff, facilities, and equipment for cardiology services might be managed centrally by a multispecialty group practice (MSGP); or the cardiac catheterization suite might be owned by an affiliated hospital. Also, the medical practice (either cardiology or MSGP) might have an affiliation with an Independent Practice Association (IPA) or physician-hospital organization (PHO) that manages (and pays for) some contracting and billing costs; such an affiliate might even provide HIT and quality improvement support (see Table 2).

Similarly, a family physician might work at a primary care site (PCS) that manages all its costs or in a site owned by a larger organization that centrally manages and accounts some or all costs. As with the cardiologist, the family physician's outpatient practice could also occur in facilities owned by an affiliated hospital so that the clinic space, equipment, and even support staff costs might be borne by the hospital. Of course, the PCS might also have an IPA or PHO affiliation providing some health plan-related or other inputs. 


\section{Potential Sources of Output Data}

Given the prominence of fee-for-service as a method of reimbursement for physician work by many purchasers across most US markets, one might anticipate that billed claims for services would be a readily available source of output data. Indeed, a number of the surveys referenced below note practice billing systems as a common source for respondent information. Nonetheless, the complex organizational environment in which physicians work now occurs may complicate the ease of acquiring relevant data from a single source. Analyses of Physician Compare data show that for a number of prominent specialties (for example, cardiology, dermatology, ophthalmology, and orthopedic surgery), over $40 \%$ of these physicians billed the Medicare program for services provided through more than one practice organization. ${ }^{31}$ Thus, even the flawed RVU data from physician work would have to be collected from multiple practices or from multiple payers. Finally, managed care plans that use capitation to pay practices may not require detailed encounter data, as payments are not tied to the delivery of specific services.

\section{THE MEASUREMENT CHALLENGE: OBTAINING RELI ABLE AND VALID MEASURES OF INPUTS AND OUTPUTS}

\section{Measuring Inputs}

To identify potential measurement approaches of inputs to medical practice, we reviewed a variety of past data collection efforts (Table 3). These data collection efforts have typically relied on either physician respondents or on responses from practice organization administrators. However, there are now various potential respondents in these often complex networks of practice affiliations (Table 2). Individual physicians could be an appropriate informant for questions related to their clinical practice at a specific site, including their personal allocation of effort, such as time devoted to administrative work like interactions with insurance companies. ${ }^{32}$ While physicians in large and multisite practices might provide reliable information on the availability and role of the other physicians, clinical support staff, and technology they work with directly at their site, they will not know the resources supporting other types of physicians in their organization.

The job title of practice administrator suggests a reliable source of information on practice inputs, but collecting information from administrators presents additional methodological challenges. There is no comprehensive list of practice administrators, and the responsibilities and scope of knowledge of individuals in this position vary across practices. Practice site administrators (once they have been identified) are likely to be the reliable respondents for information about such costs associated with support personnel, facilities, and medical equipment at specific practice location. However, some aspects of practice costs may be managed at the organizational level, so some site administrators may have either limited or no understanding of some input costs. ${ }^{33}$
Table 3 Past Data Collection Efforts to Measure Economics of Physician Practice

\section{Past Data collection Efforts}

The Physicians' Practice Costs and Income Survey from the Health Care Financing Administration (now the Centers for Medicare \& Medicaid Services, or CMS) $3,10,11,16$

The Periodic Survey of Physicians (1976-1980) and its successor, the Socioeconomic Monitoring Survey (1981-1986, 1989), from the American Medical Association (AMA) ${ }^{1}$

The Medical Group Management Association Cost Survey ${ }^{2,9,14-16}$

Mathematica Policy Research's National Survey of Medical Group

Practices (under contract with the National Center for Health Services Research), March-June $1978^{12}$

The AMA Physician Practice Costs Survey-Pilot Survey by Mathematica Policy Research ${ }^{13}$

\section{Measuring Outputs}

For all their conceptual flaws as a measure of physician output, data on physician RVUs are regularly generated in the course of fee-for-service medical practice. Unfortunately, even these are not a reliable and valid enumeration of physician work. There have been a number of problems identified with work RVUs as a measure of physician outputs. ${ }^{23,24}$ Because current RVUs have become poorly calibrated, different allocations of physician roles and clinical responsibilities can result in large variations in the seeming productivity of different physicians working in the same specialty. For example, one interventional cardiologist may spend most of her time in the catheterization lab performing procedures, while another might spend more time managing episodes of coronary artery disease that require cardiac interventions. This difference in clinical roles might cause the second cardiologist to appear to have lower overall output per hour worked (lower RVUs per hour), because more time is spent performing relatively undervalued services such as evaluation and management visits. Recalibrating work RVUs might at least partially address this imbalance. However, another problem with RVUs as a measure of output (as discussed above) is that some of the work performed to ensure desirable patient outcomes is not readily documented through current billing for physician services.

Surveys of physician practice organizations have been a common way of measuring physician outputs, but as mentioned earlier, these responses typically are reported from the billing records, with all the reliability and validity concerns of counts of patient services or of RVUs. Surveys of physicians themselves could collect data on the daily activities related to services for patients. For example, physicians can report on the number of patients they care for and their proportion of time spent in various clinical activities (for example, evaluation and management visits, interpreting test results and performing procedures) and nonclinical activities. ${ }^{1,2,13}$ Of course, physicians may not be reliable respondents if asked about the appropriateness or quality of the services they provide. ${ }^{34}$ Further, even if physicians provide reliable data on their own daily activities, their reports may not reflect a full understanding of the contributions from other members of the contemporary medical practice team. ${ }^{35}$ 


\section{Measuring Inputs and Outputs of Physician Practice: the Path Forward?}

Since the 1970s, researchers have used surveys to observe the traditional outputs of physician services such as visits and RVUs. However, recent developments in "big data," such as all-payer claims databases (APCDs), might offer new opportunities to observe the totality of output of physicians in practice organizations that rely on fee-for-service payments. Of course, these data would, at best, provide only information on the work RVUs for those services routinely recompensed by payers (that is, no information on telephone care or care coordination). Various episode groupers have been developed to use claims data to construct episodes of care, but each has limitations. ${ }^{36}$

Some quality measures can be calculated through claims, but the associated limitations have been well documented, ${ }^{28}$ and the appropriateness of few services or surgical episodes can be determined without more detailed patient-level data. ${ }^{25,28}$ Even patient surveys combined with all-payer claims data would prove insufficient for reliable measurement of physician outputs across specialties and settings.

Nonetheless, the future holds promise of more granular and comprehensive information from electronic medical record data. With such detailed information on both patient findings and clinician actions, researchers might be able to assess such outputs of physician work as correctness of diagnosis and appropriateness of management. Despite this promise, the diversity of HIT platforms, limited interoperability of current systems, and limited availability of HIT-based measures of quality and appropriateness require many hurdles to be overcome before such data can be used to measure inputs and outputs consistently across diverse professional roles and practice organizations.

There are several promising initiatives involving data sharing at the organizational level that could provide a starting point for developing and piloting such new data sources and measures of physician inputs and outputs. For example, the Mayo Clinic has partnered with Optum, the information technology-enabled health services division of UnitedHealth Group, to launch a research "lab" where clinical and claims data will be shared for research purposes. The combination of clinical data from the electronic health record system and administrative claims could allow for the creation and testing of more precise measures of health care quality and efficiency. ${ }^{37}$ The American Medical Group Association is in the process of adding additional practices to this collaboration. Data from the HMO Research Network (HMORN) could also be used to develop and pilot new metrics. HMORN maintains a virtual data warehouse containing information from member HMOs, which can be used to study health care utilization. Understanding how these networks and data sets can be used to develop and pilot new metrics could greatly advance the field of inquiry on how physician inputs and outputs are evolving in the changing health care system. Of course, all of these current initiatives reflect physicians and practice settings that are part of multispecialty medical groups, often in highly integrated systems of care. Even if such pilot work offered promise for future measurement of the inputs and outputs of physician practice, additional efforts would be required to establish data collection approaches and measurements applicable to smaller and single specialty practices.

\section{CONCLUSIONS}

Understanding the economics of medical practice remains important in view of ongoing changes in the payment, regulation and technology for physician work. However, the same evolving environment for physician practice that creates the need for this better understanding imposes interesting and important conceptual challenges in what to measure in such research. Examples identified here include the technology driven changes into the inputs for physician practice and widely documented variability in the quality and appropriateness of the units of services produced through these inputs.

Likewise, there are current and emerging data source challenges relevant to measuring these evolving constructs. The diverse affiliations for physician practice sites mean data on key practice inputs to physician work may be held in any of several organizations. Changes in physician work also result in many physicians providing services in multiple locations, often billing through different organizations.

Both these conceptual and data challenges introduce interesting measurement problems that must be overcome to facilitate research on the economics of modern medical practice. Unlike the solo physician practice model common in the early years of research on the economics of practice, physicians may vary greatly in their awareness of the inputs to their practice, and with the diverse roles of practice administrators, no single other individual may be better informed regarding the range of practice inputs. The measurement of outputs may not be much more reliable, complicated by such problems as the poor calibration of RVUs and the complexity of measuring nonbillable work, such as that done by clinical teams.

Fortunately, recent developments in data aggregation such as all-payer claims data bases and data sharing consortia across payers and delivery organizations create a potential platform that could be used in developing the needed data sources and measurement techniques. However, considerable additional methodological work will be required to overcome the aforementioned measurement and data challenges. Furthermore, the lessons learned must be applied to the broad range of physician roles and practice settings to support policy relevant research on the changing economics of medical practice.

Acknowledgements: This publication is derived from work supported under a contract with the Agency for Healthcare Research and Quality (AHRQ) ((HHSP23320095642WC/HHSP23337033T). However, this publication has not been approved by the agency. We are grateful to our technical expert panel and consultants for their feedback on an earlier version of this manuscript: Michael Barr, Larry Casalino, Doug Conrad, John Kralewski, Steve Shortell, Carol Simon, and Jane Sisk. An earlier version of this manuscript was presented at 
the Collecting Data on Physicians and their Practices technical expert panel meeting on July 23, 2014.

Conflict of Interest: The authors declare that they do not have a conflict of interest.

Corresponding Author: Christopher Fleming, MPH; Mathematica Policy Research, Princeton, NJ, USA (e-mail: cfleming@mathematicampr.com).

\section{REFERENCES}

1. Escarce J, Pauly MV. Physician opportunity costs in physician practice cost functions. J Health Econ. 1998;17(2):129-151.

2. Rosenman R, Friesner D. Scope and scale inefficiencies in physician practice. Health Econ. 2004;13(11):1091-1116.

3. Pope G, Burge RT. Economies of scale in physician practice. Med Care Res Rev. 1996;53(4):417-440.

4. Burns LB, Goldsmith JC, Sen A. Horizontal and vertical integration of physicians: a tale of two tails. Adv Health Care Manag. 2013;15:39-117.

5. Baker LC, Bundorf MK, Kessler DP. Vertical integration: Hospital ownership of physician practices is associated with higher prices and spending. Health Aff. 2014;33(5):756-763.

6. Ginsburg PB, Pawlson LG. Seeking lower prices where providers are consolidated: An examination of market and policy strategies. Health Aff. 2014;33(6): 1067-1075.

7. Robeznieks A. More cardiologists working for hospitals. Modern Healthcare, September 10, 2012. Available at: http://www.modernhealthcare.com/article/20120910/MODERNPHYSICIAN/309109974/more-cardiologists-working-for-hospitals. Accessed April 15, 2015.

8. Reinhardt U. A production function for physician services. Rev Econ Stat. 1972;54(1):55-66.

9. Hough DE, Liu K, Gans DN. Size matters: the diversity of physician practice production functions [manuscript]. Baltimore: Johns Hopkins University; 2013.

10. Brown DM, Lapan HE. Analysis of physicians' input decisions. In: Greenspan N, ed. Issues in Physician Reimbursement. HCFA Publication No. 03121. Washington, DC: Department of Health and Human Services; 1981.

11. Hurdle S, Pope G. Physician productivity: trends and determinants. Inquiry. 1989;26(1):100-115.

12. Gaynor M, Pauly MV. Compensation and productive efficiency in partnerships: evidence from medical group practice. J Polit Econ. 1990;98(3):544-573.

13. Kalb L, Sinclair M. AMA Physician practice costs-pilot survey report. Princeton: Mathematica Policy Research; 2000.

14. Andes S, Metzger LM, Kralewski J, et al. Measuring efficiency of physician practices using data envelopment analysis. Manag Care. 2002;11(11):48-54.

15. Gans D. It's the denominator stupid. MGMA Connex. 2002;2(3):20-21.

16. Weil TP. Multispecialty physician practices: fixed and variable costs, and economies of scale. J Ambul Care Manag. 2002;25(3):70-77.

17. Brown DM. Do physicians underutilize aides? J Hum Resour. 1988;23(3):342-355.

18. Reschovsky JR, Rich EC, Lake TK. Factors contributing to variations in physicians' use of evidence at the point of care. J Gen Intern Med. 2015.
19. Pham HH, Devers KJ, May JH, Berenson R. Financial pressures spur physician entrepreneurialism. Health Aff (Millwood). 2004;23(2):70-81.

20. Pham HH, Ginsburg PB. Unhealthy trends: the future of physician services. Health Aff (Millwood). 2007;26(6):1586-1598.

21. Fleming NS, Becker ER, Culler SD, et al. The impact of electronic health records on workflow and financial measures in primary care practices. Health Serv Res. 2014;49(1):405-420.

22. Conrad DA, Sales A, Liang S-Y, et al. The impact of financial incentives on physician productivity in medical groups. Health Serv Res. 2002;37(4):885-906.

23. Medicare Payment Advisory Commission. Report to the Congress: Medicare and the Health Care Delivery System. Washington, DC: Medicare Payment Advisory Commission; 2013.

24. Medicare Payment Advisory Commission. Report to the Congress: Medicare and the health care delivery system. Washington, DC: Medicare Payment Advisory Commission; 2014.

25. Lake TK, Rich EC, Stone Valenzano C, Maxfield MM. Paying more wisely: effects of payment reforms on evidence-based clinical decisionmaking. J Comp Eff Res. 2013;2(3):249-259.

26. Jaramillo E, Tan A, Yang L, et al. Variation among primary care physicians in prostate-specific antigen screening of older men. JAMA. 2013;310(15):1622-1624.

27. Weiss JM, Smith MA, Pickhardt PJ, et al. Predictors of colorectal cancer screening variation among primary care providers and clinics. Am J Gastroenterol. 2013;108(7):1159-1167.

28. Hudson Scholle S, Roski J, Dunn DL, et al. Availability of data for measuring physician quality performance. Am J Manag Care. 2009; 15(1):67-72.

29. Mehrotra A, Adams JL, Thomas JW, McGlynn EA. The effect of different attribution rules on individual physician cost profiles. Ann Intern Med. 2010;152(10):649-654.

30. Wadgaonkar AD, Schneider EC, Bhattacharyya T. Physician tiering by health plans in Massachusetts. J Bone Joint Surg Am. 2010;92(12):22042209 .

31. Hubbard M, Ballou J, Lim W, Rich E, Collins A. Observations from the physician feedback/value modifier program. Washington, DC: Mathematica Policy Research; 2015.

32. Casalino LP, Nicholson S, Gans DN, et al. What does it cost physician practices to interact with health insurance plans? Health Aff (Millwood). 2009;28(4):w533-w543.

33. Rich EC. Departmental and school-wide mission-based management: a case study. Am J Med. 2001;110(3):245-251.

34. Adams AS, Soumerai SB, Lomas J, Ross-Degnan D. Evidence of selfreport bias in assessing adherence to guidelines. Int $\mathrm{J}$ Qual Health Care. 1999;11(3): 187-192.

35. Donelan K, DesRoches CM, Dittus RS, Buerhaus P. Perspectives of physicians and nurse practitioners on primary care practice. New Engl $\mathrm{J}$ Med. 2013;368(20):1898-1906.

36. Rosen AB, Liebman E, Aizcorbe A, et al. Comparing commercial systems for characterizing episodes of care. Washington, DC: Bureau of Economic Analysis; 2012.

37. McCann E. Mayo Clinic launches data-sharing lab. Healthcare IT News, January 16, 2013. Available at: http://www.healthcareitnews.com/news/ mayo-clinic-optum-launch-data-sharing-research-lab-cambridge. Accessed April 15, 2015.

38. Conrad D, Fishman P, Grembowski D, et al. Access intervention in an integrated, prepaid group practice: effects on primary care physician productivity. Health Serv Res. 2008;43(5):1888-1905. 